\title{
A Review on Nasoalveolar Molding
}

\author{
Pazhaniswamy Manivannan ${ }^{1}$, Lidhiya Alexander ${ }^{2}$, V Vijaykumar $^{3}$
}

\begin{abstract}
A common hereditary defect of the oral cavity with grave socioeconomic problem is cleft lip and palate. Although the defect varies in forms and severity, the individuals presented with glitches regarding functions and esthetics. Authors claim that nasoalveolar molding improves facial esthetics and function and has gained more attention. The objective of presurgical nasoalveolar molding comprises improving lip segment, inferior lateral alar cartilages, and alveolar cleft segments. Outcomes of presurgical nasoalveolar molding are promising and hence are encouraged immediately after birth and continued until further corrective surgery is planned. The rationale of presurgical nasoalveolar molding is approximation of the alveolar segments, wherein the surgeon has to perform gingivoperiosteoplasty followed by corrective lip surgery.
\end{abstract}

Keywords: Cleft, Gingivaperiosteoplasty, Nasoalveolar molding.

Journal of Scientific Dentistry (2020): 10.5005/jp-journals-10083-0922

\section{BACKGROUND}

Cleft lip, alveolus, and palate are the common congenital defects of head and neck. The prevalence of cleft lip and palate are $27,000-33,000$ of the 24.5 million births per year. ${ }^{1}$ The incidence of cleft lip and palate is 1 in 781 live births. Comparing the type of clefts, unilateral clefts are nine times as common as bilateral clefts, and tail two times frequently on the left than on the right. Males have a high risk of cleft lip and palate, whereas females are at risk of isolated cleft palate. ${ }^{2,3}$

The patients with cleft lip and palate should be approached in a multidisciplinary setup. In the recent decades, it has evolved due to the availability of advanced surgical techniques. The rudimentary management objective is to reinstate normal function and structure.

Presurgical nasoalveolar molding is an atraumatic way of preparing the gums, lips, and nostrils prior to the surgery, thus eliminating the severity of the cleft. Several surgeries were planned for correcting cleft lip and palate before the introduction of presurgical nasoalveolar molding.

\section{Principles of Presurgical Nasoalveolar Molding}

Negative sculpturing and passive molding of the alveolus and adjacent soft tissues are the main principles of presurgical nasoalveolar molding. The passive molding is carried out by molding a custom-made acrylic plate that directs the growth of the alveolus. Simultaneously internal surfaces are modified to get the anticipated form of the alveolus and nose by either adding or removing the material in specified areas termed as negative sculpturing.

\section{Aims and Objectives}

- Prime objective is to reduce the severity of cleft malformation and to aid in surgery.

- Nonsurgical broadening of columella.

- Estimating the closure of lip segments.

- To aid in additional bone formation.

\section{Materials and Methods}

In newborns with bilateral cleft lip and palate, the goal is to lengthen the columella nonsurgically and to center the premaxilla \begin{tabular}{l}
\hline \hline${ }^{1-3}$ Department of Orthodontics and Dentofacial Orthopedics, Indira \\
Gandhi Institute of Dental Sciences, Sri Balaji Vidyapeeth, Puducherry, \\
India \\
Corresponding Author: Pazhaniswamy Manivannan, Department of \\
Orthodontics and Dentofacial Orthopedics, Indira Gandhi Institute of \\
Dental Sciences, Sri Balaji Vidyapeeth, Puducherry, India, Phone: +91 \\
8056653813, e-mail: vickyjacks04@gmail.com \\
How to cite this article: Manivannan P, Alexander L, Vijaykumar V. \\
A Review on Nasoalveolar Molding. J Sci Dent 2020;10(2):49-50. \\
Source of support: Nil \\
Conflict of interest: None
\end{tabular}

along the midsagittal plane. The nasoalveolar molding involves the lengthening of columella by moving the ala of nasal vaults anteriorly in a sagittal direction. ${ }^{4}$

\section{Steps}

Evaluation of presurgical nasoalveolar molding should be started at birth. The scientific procedure and construction of the presurgical nasoalveolar molding plate should be started on the first week. Since the level of the circulating estrogen and hyaluronic acid in infants is higher, molding of the tissues is comparatively easier in infants. Hence, presurgical nasoalveolar molding should be done before 6 months of age. ., $^{5}$

\section{Impression Technique}

The first impression is made with heavy-bodied silicone impression material as soon as the child is born, as the cartilage is flexible and formable. A novel technique was performed by holding the newborn upside down, so that the tongue is in the forward position. ${ }^{7}$ The constructed plate must be in place till the siliconbodied material begin to extrude from the posterior border. Yang et al. used a pretrimmed pediatric tray with the infant in the erect position being held by the parent. Prashanth et al. and Mishra et al. made impression when the newborn was in upright position placed on the lap of the parent. A new technique to make impression using ice-cream sticks and impression compound was also explained by various authors. ${ }^{8}$ The impression will be allowed to set and the cast is poured with which the custom trays are fabricated and 
secondary impression is made. An acrylic plate is fabricated with the secondary impression cast.

\section{Appliance Fabrication}

Undercuts have to be blocked with utility wax. The plate as mentioned by Grayson and Maull is made of rigid, self-cure acrylic. It has to be creased with a thin layer of a denture lax. The holding arm should be made up to $40^{\circ}$ to get the suitable stimulation and to elude dislodgment. The arm must be placed at the junction between the upper and lower lips. ${ }^{9}$ The holding buttons with the aid of elastics and masking tape fortify the molding plate in the oral cavity.

\section{Appliance Insertion}

The masking tapes are used to retain the plates in the oral cavity. The elastics of 0.25 inch can be used by stretching two times their length. In case of unilateral clefts, one retention arm is used and is placed on the anterior end of the appliance. ${ }^{10}$ The upper and lower lip segments are approximated without the lower lip being obstructed when the retention arm is in position or in the junction of upper and lower lips. The infant is bottle fed to ensure good suckling without gagging. Close fitting of lip segments with masking tape aids in holding the plate and advancing the position of the nasal base area by carrying the columella near the midsagittal plane.

The review appointments are planned every week to adjust the molding plate by marking trim or addition of acrylic. As the alveolar gap closes, the lip segments also close reducing the nasal base width. ${ }^{11}$

\section{Nasal Stents}

Nasal stents are incorporated when the alveolar gap width is less than $5 \mathrm{~mm}$. It resembles the shape of a kidney and is added to the vestibular shield of the appliance. The tip of the nasal stents is to be pointy in the way of the medial wall of the defective nostril. ${ }^{12}$ The upper lobe elevates the dome until blanching is evident and the inferior part raises the nostril tip and outlines the top of columella. Major surgical closure has to be planned between 3 months and 5 months of age. ${ }^{13}$

\section{Complications}

- Irritation of oral mucosa.

- More force application causes inflammation.

- The plate when dislodged accidentally can cause airway obstruction.

- Nasoalveolar molding appliance may drop down to the floor of the mouth when the holding arms are tapped horizontally.

\section{Benefits}

It provides healthier result with minor scar. It reduces the cleft side nasal warps, upsurges the length of columella, and makes the prolabium visible. Literature suggests that the shape of the nose is stable with better lip and nasal form. ${ }^{14}$ Nasoalveolar molding reduces the amount of revision surgeries. Studies have shown that patients treated with nasoalveolar molding and gingivoperiosteoplasty did not necessitate secondary bone graft. Studies have shown nasoalveolar molding to be cost-effective. ${ }^{15}$

\section{Conclusion}

Nasoalveolar molding has significantly improved the surgical outcome of cleft lip and palate patients. Studies have proved that molding used to decrease the cleft abnormality does not constrain midfacial growth. Despite a lot of research and high-level evidence, nasoalveolar molding still deserves further study.

\section{References}

1. Banerjee M, Dhakar AS. Epidemiology-clinical profile of cleft lip and palate among children in India and its surgical consideration. J Surg 2013;2:45-51.

2. Sharma MP, Sandhu BH, Kumar MA. Presurgical nasoalveolar molding in unilateral cleft lip and palate patient. Indian J Dent Adv 2012;4:1024-1029.

3. Grayson BH, Maull D. Nasoalveolar molding for infants born with cleft $s$ of the lip, alveolus, and palate. Clin Plast Surg 2004;31(2):149-158. DOI: 10.1016/S0094-1298(03)00140-8.

4. Goodacre Y, Swan MC. Cleft lip and palate: Current management. Paediatr Child Health 2008;18(6):283-292. DOI: 10.1016/j. paed.2008.03.008.

5. Mishra B, Singh AK, Zaidi J, Singh GK, Agrawal R, Kumar V. Presurgical nasoalveolar molding for correction of cleft lip nasal deformity: experience from Northern India. J Plastic Surg 2010;10:443-457.

6. Grayson BH, Shetye PR. Presurgical nasoalveolar moulding treatment in cleft lip and palate patients. Indian J Plast Surg 2009;42(Suppl):S56S61. DOI: 10.4103/0970-0358.57188.

7. Kim JS, Kim YJ, Nam SH, Kim HJ. Effect of pre-surgical nasoalveolar molding in unilateral cleft lip and palate infants. J Korean Acad Pediatr Dent 2013;40:209-215.

8. Dubey RK, Gupta DK, Chandraker NK. Presurgical nasoalveolar molding: a technical note with case report. Indian J Dent Res Rev 2011;2:66-68.

9. Yang S, Stelnicki EJ, Lee MN. Use of nasoalveolar molding appliance to direct growth in newborn patient with complete unilateral cleft lip and palate. Pediatr Dent 2003;25(3):253-256.

10. Retnakumari N, Divya S, Meenakumari S, Ajith PS. Nasoalveolar molding treatment in presurgical infant orthopedics in cleft lip and cleft palate patients. Arch Med Health Sci 2014;29(1):36-47. DOI: 10.4103/2321-4848.133804.

11. Grayson BH, Garfi Nkle JS. Early cleft management: the case for nasoalveolar molding. Am J Orthod Dentofacial Orthop 2014;145(2):134-142. DOI: 10.1016/j.ajodo.2013.11.011.

12. Prashanth CS, Amarnath BC, Dharma RM, Dinesh AM. Cleft orthopedics using liou's technique - a case report. IOSR J Dent Med Sci 2013;12:11-15.

13. Soltan-Karimi V, Poorsattar Bejeh Mir A. Presurgical nasoalveolar molding in a neonate with bilateral cleft lip and palate: report of a case. J Compr Pediatr 2012;3(1):86-89. DOI: 10.17795/ compreped-5421.

14. Upadhyay U, Agarwal P, Loomba A. Thermoplastic base plate modification of nasoalveolar molding device. J Asian Pac Orthod Soc 2011;2(2):4-5.

15. Grayson BH, Santiago PE, Brecht LE, Cutting CB. Presurgical nasoalveolar molding in infants with cleft lip and palate. Cleft Palate Craniofac J 1999;36(6):486-498. DOI: 10.1597/15451569_1999_036_0486_pnmiiw_2.3.co_2. 